Article

\title{
Structural Transformations in Crystals Induced by Radiation and Pressure. Part 10. The Crystallographic Picture of Photochemical Behaviour of bi(anthracene- 9,10-dimethylene) under High Pressure
}

\author{
Julia Bąkowicz *(1) and Ilona Turowska-Tyrk $(\mathbb{0}$ \\ Advanced Materials Engineering and Modelling Group, Faculty of Chemistry, Wrocław University of Science \\ and Technology, Wybrzeże Wyspiańskiego 27, 50-370 Wrocław, Poland; ilona.turowska-tyrk@pwr.edu.pl \\ * Correspondence: julia.bakowicz@pwr.edu.pl; Fax: +48-71-320-33-64
}

Received: 22 October 2020; Accepted: 10 November 2020; Published: 12 November 2020

\begin{abstract}
The results of the monitoring of the $[4+4]$ photocycloaddition reaction path in single crystals of bi(anthracene-9,10-dimethylene) at high pressure are presented. The crystal structures for several steps of the phototransformation at $0.3 \mathrm{GPa}$ and $1.0 \mathrm{GPa}$ were determined and analysed. The applied high pressure did not halt the photochemical reaction and almost $100 \%$ of the product molecules were obtained, although the reaction was very slowly reversible similarly to that of ambient conditions. During the crystal phototransformation the intramolecular geometry, molecular orientation and intermolecular interactions of the reactant changed more and more towards the values observed for the product. The initial increase in the unit cell volume brought about by the photochemical reaction was diminished by high pressure. High pressure itself did not significantly influence the intramolecular geometry of the reactant and product molecules, but it influenced the intermolecular interactions.
\end{abstract}

Keywords: single crystal X-ray structure analysis; high-pressure crystallography; $[4+4]$ photocycloaddition reaction

\section{Introduction}

Mechanochemistry is the broad field of research where external mechanical force is used to induce the breaking of intramolecular chemical bonds, which is followed subsequently by a chemical reaction [1]. The mechanical force can be generated inter alia by isotropic hydrostatic pressure [2,3]. The mechanochemical approach was applied to a variety of compounds and reactions $[1,4]$. One of the compounds was bi(anthracene-9,10-dimethylene).

Molecules of bi(anthracene-9,10-dimethylene), (1), are sensitive to visible light and undergo the intramolecular [4+4] photocycloaddition in solution and solid state [5-9]. As a result of this photochemical reaction, two additional covalent bonds between the anthracene moieties are formed (Scheme 1) and the middle ring of both anthracene moieties loses its aromaticity. The reaction is reversible in the dark or at increased temperature [6,10-12]. The molecules of the photoproduct in a crystalline state slowly convert back to the reactant during ca. 40-days in ambient conditions [5]. 

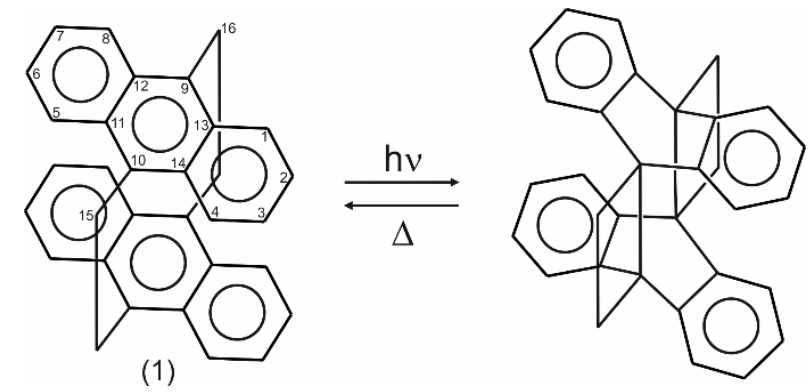

Scheme 1. The equation of the $[4+4]$ photocycloaddition for bi(anthracene-9,10-dimethylene) with the numbering of atoms.

The results of monitoring the path of the photochemical reaction in ambient conditions were published in [5]. The reaction brought about some changes in the molecular and crystal geometry. For instance, the changes were observed for the unit cell parameters, the molecular shape and orientation. The most interesting variations were for the geometry of the reaction centre, and were rationalized by the stress imposed on reactant molecules by product molecules and also by the rigidity of reactant molecules.

Molecules of (1) are known to crystallise in two types of crystals: $\alpha$ and $\beta[2,6,13,14]$. These two crystalline forms differ in the mutual arrangements of anthracene moieties $[2,6,13,14]$. In the crystal of the $\alpha$-form, the moieties are mutually rotated around the axis normal to the plane of the anthracenes, while in the case of the $\beta$-form they are related by a centre of symmetry. The atomic coordinates were only given for the $\beta$-form (CSD, refcodes ANTMEU, ANTMEU01 and ANTMEU03) $[5,9,15]$. The single crystals of the $\beta$-form are studied in this paper.

In the scientific literature, the spectroscopic studies on the influence of high pressure on the reversibility of the reaction of (1) are known [2]. Nevertheless, in those studies the sample was prepared in a polymer matrix, not as a single crystal. The authors stated that two reverse reactions, with two different rate constants $\mathrm{k}_{1}$ and $\mathrm{k}_{2}$, can occur in the polymer matrix. One reaction is sensitive to pressure (rate constant $\mathrm{k}_{1}$ is, for instance, $0.0003,0.0343$ and $0.0788 \mathrm{~min}^{-1}$ at $0.1 \mathrm{MPa}, 0.93 \mathrm{GPa}$ and $1.95 \mathrm{GPa}$, respectively) and the second one is insensitive to it $\left(\mathrm{k}_{2}=0.0012 \mathrm{~min}^{-1}\right.$ at each pressure), and above 2.0 GPa, the formation of the photoproduct is entirely inhibited.

On the grounds of our studies presented in this paper, we stated that in single crystals, the reverse reaction does not dominate at applied high pressures. Owing to this, it was possible to determine the crystal structures containing product molecules and to monitor the crystal phototransformation of (1). The obtained results were also compared with the respective data for ambient pressure in order to gain information about the influence of high pressure on the structural changes brought about by the $[4+4]$ photocycloaddition. The studies will enrich knowledge of crystal transformations under high pressure.

\section{Materials and Methods}

Single crystals of the studied compound (1) were recrystallized from a mixture of toluene and chloroform (vol. 1:1). The obtained crystals were very thin. This affected the data quality, i.e., the high values of $R_{\text {int }}$ and $\mathrm{R}$-factors. The $\mathrm{X}$-ray diffraction studies were carried out in the conditions of ambient temperature and high pressure. The high pressure was created in a diamond anvil cell (DAC) [16]. Since the crystals of (1) are very sensitive to daylight, all the experiments (i.e., the selection of crystals, the loading of the DAC and the X-ray diffraction measurements) were conducted in a darkroom. In order to prepare the sample, the crystal was illuminated a few times with visible light of very low power (minimum power of microscope backlight) for a very short time. Even though it could induce the photoreaction in the crystal in a slight degree, it was insignificant in comparison to irradiating the crystal for minutes with a bright $100 \mathrm{~W}$ mercury lamp. The selected crystal of (1), together with a quartz crystal were placed between two diamonds of the DAC in a hole of $0.4 \mathrm{~mm}$ diameter drilled in an inconel gasket. The entirety was filled with a hydrostatic fluid, which was a mixture of glycerine 
and water (vol. 3:2). The quartz crystal was used as a pressure sensor. The value of pressure was determined on the basis of the changes in the unit cell parameters of quartz [17]. The experiments were conducted for two single crystals: at $0.3 \mathrm{GPa}$ and $1.0 \mathrm{GPa}$.

In order to induce the photochemical reaction, the crystals studied were irradiated in the DAC by means of a mercury lamp. The beam was transmitted by water and a suitable glass filter. The water filter protected the crystals from heating up. As a glass filter the same one was used as for the studies carried out in ambient conditions [5], i.e., GG-455, which transmitted wavelengths longer than $440 \mathrm{~nm}$ (ca. $95 \%$ transmittance for $\lambda>485 \mathrm{~nm}$ ). The irradiation times at $0.3 \mathrm{GPa}$ were 5 and $15 \mathrm{~min}$ in total and at 1.0 GPa were 0,5 and 15 min in total.

After each time of irradiation, the high-pressure X-ray data were collected [18] and the crystal structures of the pure reactant and partly reacted crystals were determined. The data collection at 0.3 GPa was repeated again after 3 and 12 weeks of the crystal kept in darkness. In such conditions, in the crystal of (1), the reverse reaction takes place. During the structure determination, it was possible to obtain the percentage content of product molecules in the crystal on the grounds of the site occupation factor. The percentage product content was as follows: $41.1,86.1,82.8$ and $0 \%$ for $5 \mathrm{~min}, 15 \mathrm{~min}, 3$ weeks and 12 weeks, respectively at $0.3 \mathrm{GPa}$ and $0,47.7$ and $90.6 \%$ for 0,5 and $15 \mathrm{~min}$, respectively, at $1.0 \mathrm{GPa}$. The standard uncertainties were in the range $1.3-1.8 \%$ and they were typical for high-pressure structures. The structures were refined by means of the SHELXL program $[19,20]$. The initial atomic coordinates were taken from the pure reactant and pure product crystal structures determined in ambient conditions [5]. In the case of the structures of the pure reactant, from six to eight carbon atoms of the asymmetric unit were refined anisotropically. The remaining atoms were treated isotropically. All $\mathrm{H}$ atoms were positioned geometrically with $\mathrm{U}_{\text {iso }}=1.2 \mathrm{U}_{\text {eq }}$ of the respective carbon atom. For the partly reacted crystal structures, the $\mathrm{C} 1 \rightarrow \mathrm{C} 13$ and $\mathrm{C} 5 \rightarrow \mathrm{C} 11$ benzene rings were considered as rigid rotating groups. In order to model the observed reactant-product disorder, we used the weak restraints DFIX, DANG, FLAT and SIMU, which restrained bond lengths, valence angles, fragment planarity and displacement parameters for some atoms. It is worth adding that as is known from the studies carried out in ambient conditions [5], the crystals of (1) are not sensitive to X-ray radiation, i.e., X-rays do not influence the photoreaction. Selected crystallographic and experimental data were gathered in Table 1. CCDC 1853207-1853213 contains the supplementary crystallographic data for this paper. These data can be obtained free of charge via http://www.ccdc.cam.ac.uk/conts/retrieving.html (or from the CCDC, 12 Union Road, Cambridge CB2 1EZ, UK; Fax: +44-1223-336033; E-mail: deposit@ccdc.cam.ac.uk). 
Table 1. The crystallographic and experimental data for (1).

\begin{tabular}{|c|c|c|c|c|c|c|c|}
\hline \multirow{2}{*}{$\begin{array}{c}\text { Pressure } \\
\text { Reaction progress/\% }\end{array}$} & \multicolumn{4}{|c|}{$0.3 \mathrm{GPa}$} & \multicolumn{3}{|c|}{$1.0 \mathrm{GPa}$} \\
\hline & 0 & 41.1 & 82.8 & 86.1 & 0 & 47.7 & 90.6 \\
\hline Chemical formula & $\mathrm{C}_{32} \mathrm{H}_{24}$ & $\mathrm{C}_{32} \mathrm{H}_{24}$ & $\mathrm{C}_{32} \mathrm{H}_{24}$ & $\mathrm{C}_{32} \mathrm{H}_{24}$ & $\mathrm{C}_{32} \mathrm{H}_{24}$ & $\mathrm{C}_{32} \mathrm{H}_{24}$ & $\mathrm{C}_{32} \mathrm{H}_{24}$ \\
\hline Formula Weight & 408.51 & 408.51 & 408.51 & 408.51 & 408.51 & 408.51 & 408.51 \\
\hline Crystal dimensions/mm & $0.40 \times 0.14 \times 0.05$ & $0.40 \times 0.14 \times 0.05$ & $0.40 \times 0.14 \times 0.05$ & $0.40 \times 0.14 \times 0.05$ & $0.34 \times 0.13 \times 0.06$ & $0.34 \times 0.13 \times 0.06$ & $0.34 \times 0.13 \times 0.06$ \\
\hline Crystal system & Monoclinic & Monoclinic & Monoclinic & Monoclinic & Monoclinic & Monoclinic & Monoclinic \\
\hline Space group & $\mathrm{P} 2_{1} / \mathrm{c}$ & $\mathrm{P} 2_{1} / \mathrm{c}$ & $\mathrm{P} 2{ }_{1} / \mathrm{c}$ & $\mathrm{P} 2_{1} / \mathrm{c}$ & $\mathrm{P} 2_{1} / \mathrm{c}$ & $\mathrm{P} 2_{1} / \mathrm{c}$ & $\mathrm{P} 2_{1} / \mathrm{c}$ \\
\hline $\mathrm{a} / \AA$ & $10.181(2)$ & $10.152(4)$ & $9.907(3)$ & $9.824(3)$ & $10.0600(16)$ & $10.012(4)$ & $9.733(3)$ \\
\hline $\mathrm{b} / \AA ̊$ & $12.713(6)$ & $12.805(9)$ & $12.914(8)$ & $12.922(8)$ & 12.604(7) & $12.719(11)$ & $12.830(9)$ \\
\hline$c / \AA$ & $8.416(3)$ & $8.413(5)$ & $8.462(4)$ & $8.495(5)$ & $8.3382(18)$ & $8.338(3)$ & $8.420(3)$ \\
\hline$\beta /{ }^{\circ}$ & $112.44(3)$ & $112.70(5)$ & $112.30(4)$ & $112.31(4)$ & $112.03(2)$ & $112.69(4)$ & $112.46(3)$ \\
\hline $\mathrm{V} / \AA^{3}$ & $1006.8(7)$ & $1008.9(11)$ & $1001.6(9)$ & $997.7(9)$ & $980.1(6)$ & $979.6(10)$ & $971.7(8)$ \\
\hline Z & 2 & 2 & 2 & 2 & 2 & 2 & 2 \\
\hline $\mathrm{D}_{\mathrm{x}} / \mathrm{Mg} \mathrm{m}^{-3}$ & 1.348 & 1.345 & 1.354 & 1.360 & 1.384 & 1.385 & 1.396 \\
\hline$\mu / \mathrm{mm}^{-1}$ & 0.08 & 0.08 & 0.08 & 0.08 & 0.08 & 0.08 & 0.08 \\
\hline $\mathrm{T} / \mathrm{K}$ & 299 & 299 & 299 & 299 & 299 & 299 & 299 \\
\hline Reflections collected & 4007 & 4192 & 4067 & 4059 & 3804 & 4036 & 3964 \\
\hline Reflections independent & 795 & 820 & 792 & 783 & 715 & 759 & 758 \\
\hline Reflections observed & 391 & 302 & 320 & 344 & 407 & 286 & 335 \\
\hline Completeness/\% & 43.2 & 43.7 & 43.3 & 42.8 & 39.4 & 43.2 & 42.8 \\
\hline $\mathrm{R}_{\text {int }}$ & 0.111 & 0.226 & 0.186 & 0.154 & 0.134 & 0.232 & 0.186 \\
\hline $\mathrm{R}\left(\mathrm{F}^{2}>2 \sigma\left(\mathrm{F}^{2}\right)\right), \mathrm{wR}, \mathrm{S}$ & $0.141,0.433,1.48$ & $0.184,0.511,1.32$ & $0.152,0.455,1.28$ & $0.151,0.458,1.47$ & $0.130,0.390,1.30$ & $0.155,0.456,1.21$ & $0.139,0.444,1.34$ \\
\hline$\Delta \rho_{\max }, \Delta \rho_{\min } / \mathrm{e}^{-3}$ & $0.31,-0.30$ & $0.23,-0.30$ & $0.32,-0.31$ & $0.43,-0.32$ & $0.43,-0.48$ & $0.22,-0.28$ & $0.29,-0.31$ \\
\hline
\end{tabular}




\section{Results and Discussion}

The $[4+4]$ photocycloaddition in single crystals of (1) occurs not only in ambient conditions as is known from the literature [5], but also at high pressure, as is demonstrated by the studies presented in this paper. We monitored the course of this reaction by X-ray structure analysis to almost $100 \%$ of the reaction progress for two different values of high pressure: $0.3 \mathrm{GPa}$ and $1.0 \mathrm{GPa}$. The reaction was not halted by the applied pressure and we did not observe the pressure-induced dissociation reaction in single crystals (the reverse reaction, see Scheme 1). The observed behaviour contrasts with the one observed for the compound in a polymeric matrix reported in previous studies [2]. We also stated that we had only the crystals of the $\beta$ form.

The first symptoms of the photochemical reaction occurring in the crystals of (1) are the changes in the unit cell parameters and cell volume. These changes were monitored with the reaction progress under ambient and high pressure are presented in Figure 1. As can be seen, they are smooth and their character is the same for $0.3 \mathrm{GPa}$ and $1.0 \mathrm{GPa}$ and consistent with the change in ambient conditions [5]. The most interesting relationship is connected with the variation in the cell volume. Namely, for ambient conditions the unit cell volume increases by $8.6 \AA^{3}$ from the beginning of the reaction until ca. the $40 \%$ content of the product and afterwards decreases. A similar dependence is observed at $0.3 \mathrm{GPa}$, nevertheless, the initial increase is smaller than at ambient pressure, and for $1.0 \mathrm{GPa}$ the unit cell volume is constant until $50 \%$ progress of the reaction has been completed. Hence, the conclusion is that the structural changes brought about by the photochemical reaction are reduced by pressure or even completely halted. A similar statement was also formulated for the compound undergoing another type of intramolecular photochemical reaction-that being the Norrish-Yang reaction [21].

The changes observed in the values of the cell parameters along with the progress of the crystal phototransformation are the consequence of the decrease in the number of reactant molecules and the increase in the number of product molecules having different shape/size [5]. In general, the changes in the molecular size and shape have an impact on the packing of molecules and, in this way, on the cell parameters. However, the situation is more complex, because the molecular geometry is not constant throughout the transformation of the crystal from the pure reactant towards the pure product [5].

The unit cell volume for the pure reactant crystals decreases along with the increase in pressure. For compound (1) this volume changes from $1020.5 \AA^{3}$ throughout $1006.8 \AA^{3}$ to $980.1 \AA^{3}$ for $0.1 \mathrm{MPa}$, $0.3 \mathrm{GPa}$ and $1.0 \mathrm{GPa}$, respectively, i.e., by $4.0 \%$ in transit from $0.1 \mathrm{MPa}$ to $1.0 \mathrm{GPa}$ and by $2.6 \%$ from $0.3 \mathrm{GPa}$ to $1.0 \mathrm{GPa}$. In the case of naphthalene, the variation in the unit cell volume reached $10.8 \%$ in transit from 0.1 MPa to 1.0 GPa and 5.1\% from 0.4 GPa to 1.0 GPa and for benzene 5.5\% in transit from $0.3 \mathrm{GPa}$ to $1.1 \mathrm{GPa}$ [22-25]. As can be noticed, for the very similar range of pressure the percentage change in the unit cell volume is much smaller for compound (1). This observation can be rationalized by the existence of intermolecular interactions between two adjacent molecules of naphthalene/benzene, which can be easily modified by high pressure, while in the case of (1) the two aromatic rings are connected by covalent bonds, which are extremely hard to be shortened by high pressure.

Molecules in crystals of (1) form the layers separated by the layers of voids parallel to the $b c$ plane (Figure 2). The volume of these voids per one-unit cell $\left(96,86\right.$ and $60 \AA^{3}$ at $0.1 \mathrm{MPa}, 0.3 \mathrm{GPa}$ and $1.0 \mathrm{GPa}$, respectively) decreases non-linearly along with the increase in pressure. This non-linearity is understandable since it is more and more difficult to move molecules closer to each other along with the increase in pressure. A careful analysis indicates that the shape of the voids changes near isotropically with pressure (Figure 2). 

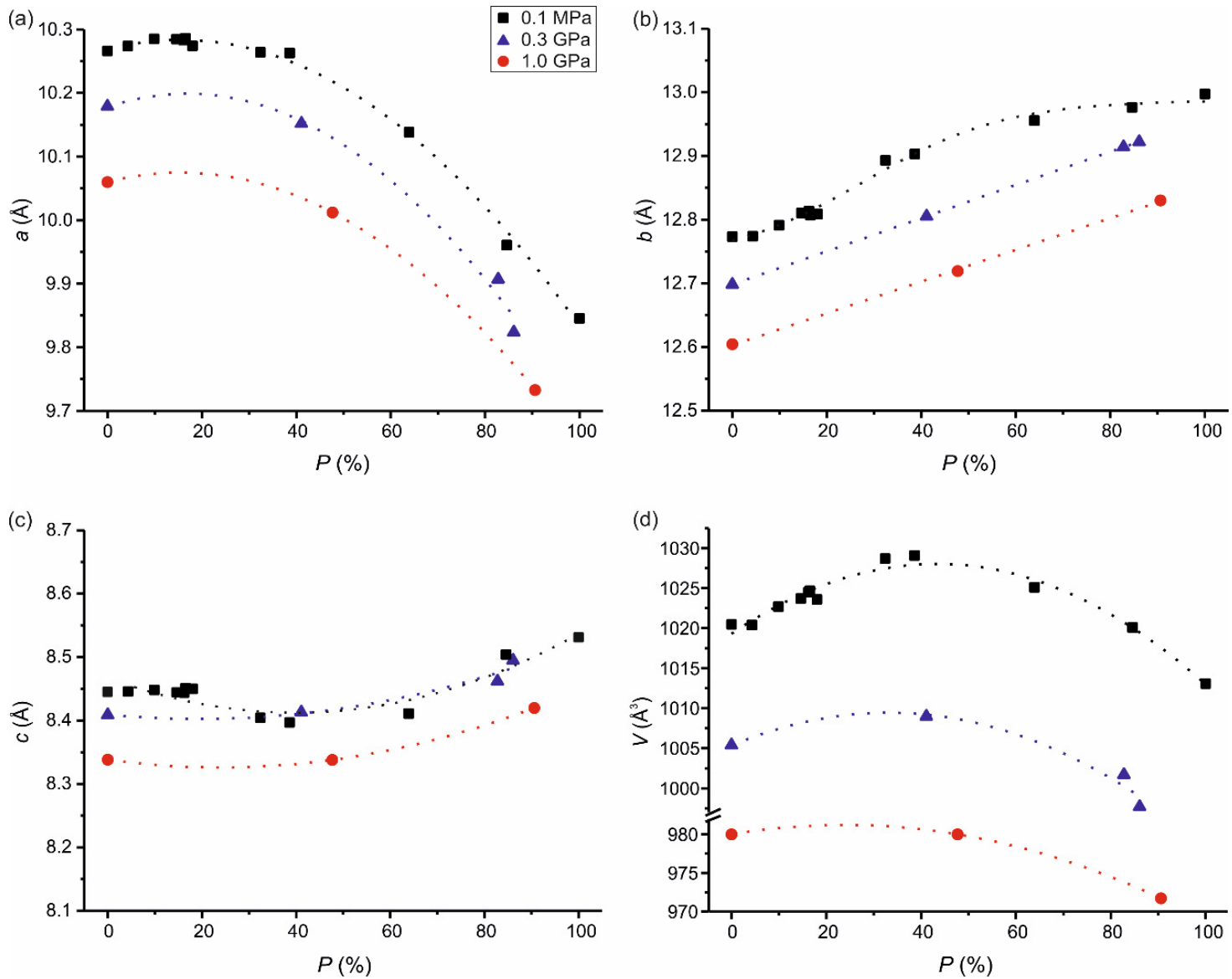

Figure 1. The variations in $(\mathbf{a}-\mathbf{c})$ the unit cell parameters and (d) the cell volume for $(\mathbf{1})$ with the reaction progress ( $P$-the content of the product in the crystal) at $0.1 \mathrm{MPa}, 0.3 \mathrm{GPa}$ and $1.0 \mathrm{GPa}$. For a better comparison the range of the axes for plots $(\mathbf{a}-\mathbf{c})$ was set to be the same. The data for $0.1 \mathrm{MPa}$ were taken from [5].

(a)

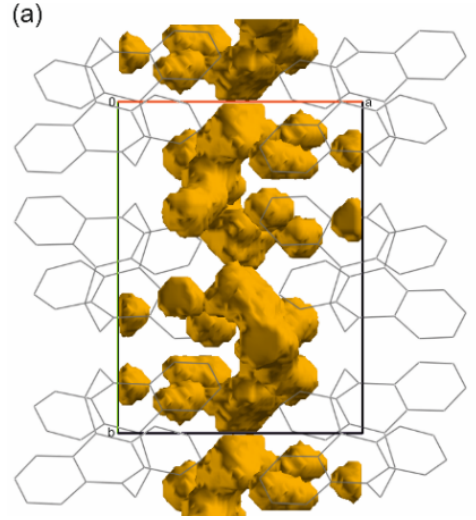

(b)

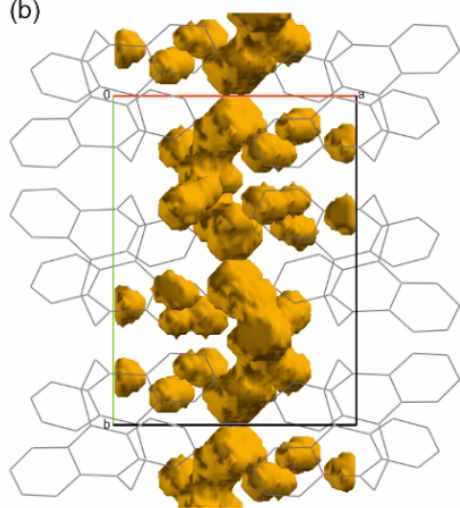

(c)

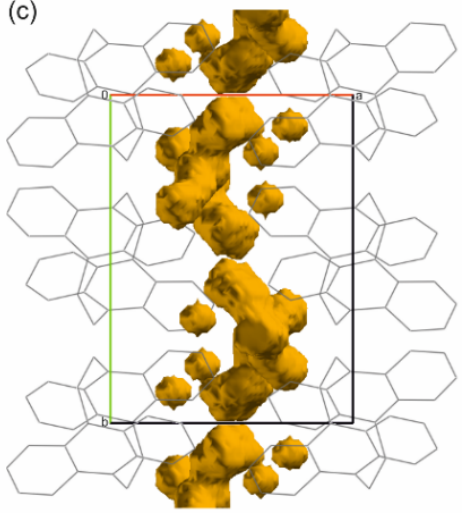

Figure 2. Molecules and voids in the crystal of (1) at (a) $0.1 \mathrm{MPa}$, (b) $0.3 \mathrm{GPa}$ and (c) $1.0 \mathrm{GPa}$. The data for the preparation of part (a) were taken from [5]. The voids were calculated by means of Mercury 3.9 [26] with the probe radius $0.6 \AA$ and grid $0.2 \AA$.

Analysing the shape of reactant and product molecules of (1), we can notice that the product molecule has a butterfly-like shape in a much higher degree than the reactant molecule (Figure 3). The difference in the shape can be described quantitatively by the angle between the planes of the halves of the anthracene ring. In ambient conditions, the value of this angle is $18.76(7)^{\circ}$ and $50.70(7)^{\circ}$ 
for the molecules in the pure reactant and the pure product crystals, respectively [5]. This shows that the difference between the reactant and product is large. As results from the studies presented in this paper, high pressure itself does not notably influence the intramolecular geometry. For the pure reactant crystal of (1), the value of the "butterfly" angle at high pressure is similar to the angle at ambient conditions and is $17.7(5)^{\circ}$ and $18.8(5)^{\circ}$ at $0.3 \mathrm{GPa}$ and $1.0 \mathrm{GPa}$, respectively, which is statistically constant at the $3 \sigma$ level. Moreover, the molecular volume of the reactant is also constant: $461 \AA^{3}$ for ambient and high-pressure conditions (the molecular volume was calculated as the difference between the volumes of the unit cell and the free space divided by the number of molecules in the unit cell). In the case of the product molecule, the value of the "butterfly" angle remains approximately identical with the increase in pressure. Namely, it is $50.7(6)^{\circ}$ for $0.3 \mathrm{GPa}$ and $86.1 \%$ of the crystal transformation and $50.2(6)^{\circ}$ for $1.0 \mathrm{GPa}$ and $90.6 \%$ of the crystal transformation.

(a)

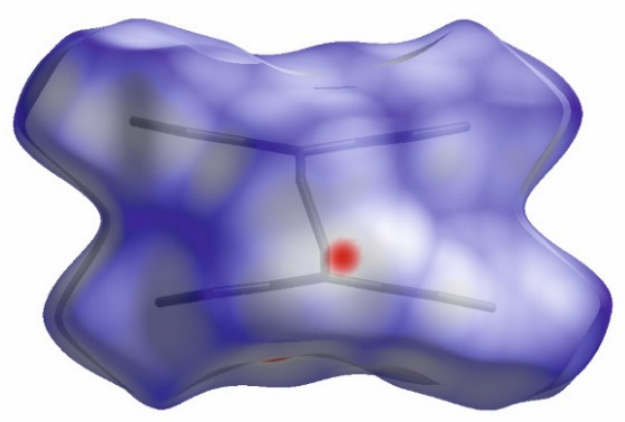

(c)

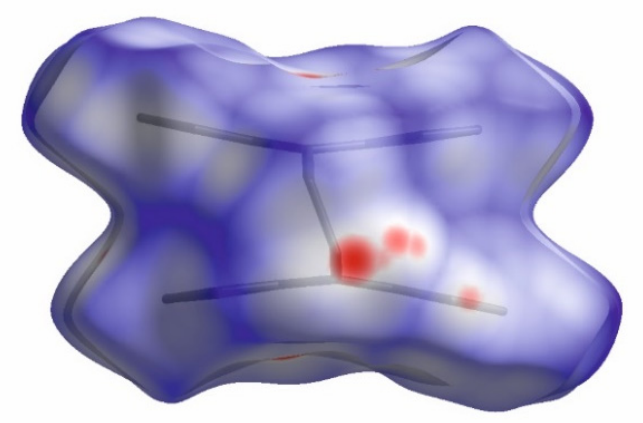

(b)

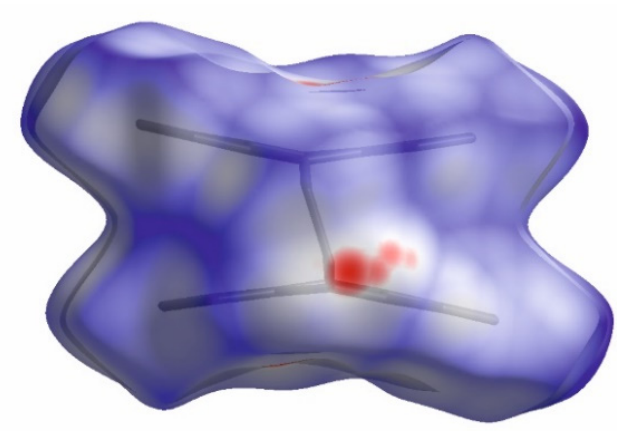

(d)

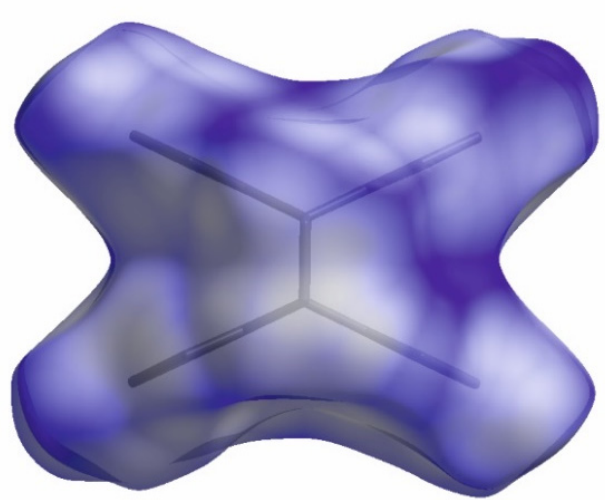

Figure 3. The Hirshfeld surfaces $[27,28]$ for the reactant molecule at (a) $0.1 \mathrm{MPa}$, (b) $0.3 \mathrm{GPa}$, (c) $1.0 \mathrm{GPa}$ and for (d) the product molecule at $0.1 \mathrm{MPa}$. The data for the preparation of parts (a) and (d) were taken from [5]. The molecular skeletons seen inside the surfaces reveal the differences in the "butterfly" angles (see the text).

However, the molecular shape was highly influenced by the progress of the crystal phototransformation and the stress induced by molecules. The relationship between the "butterfly" angle along with the reaction progress for $0.1 \mathrm{MPa}, 0.3 \mathrm{GPa}$ and $1.0 \mathrm{GPa}$ is shown in Figure 4 . As can be seen, the character of the presented relationships is similar for ambient and high-pressure conditions, since according to the above the high pressure does not influence the intramolecular geometry. Moreover, the values of the discussed angle for the reactant molecule move towards the value observed for the product molecule, which is ca. $40^{\circ}$ in the crystal at the beginning of the phototransformation and ca. $50^{\circ}$ at the end. As the "butterfly" angle in the reactant molecule is influenced by the created product molecules, the "butterfly" angle in the product molecule is influenced by the reactant molecules still existing in the crystals. This also means that the shape of the reactant is slightly different at different stages of the crystal phototransformation, and the same is valid for the product molecule. 
(a)

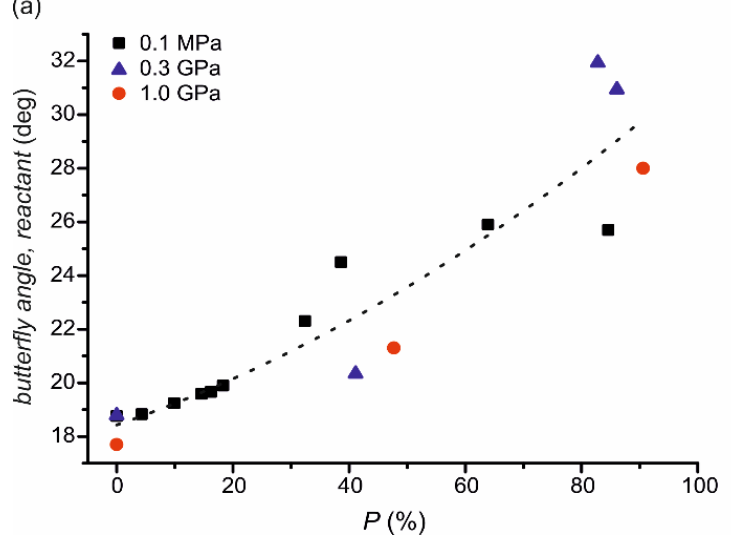

(b)

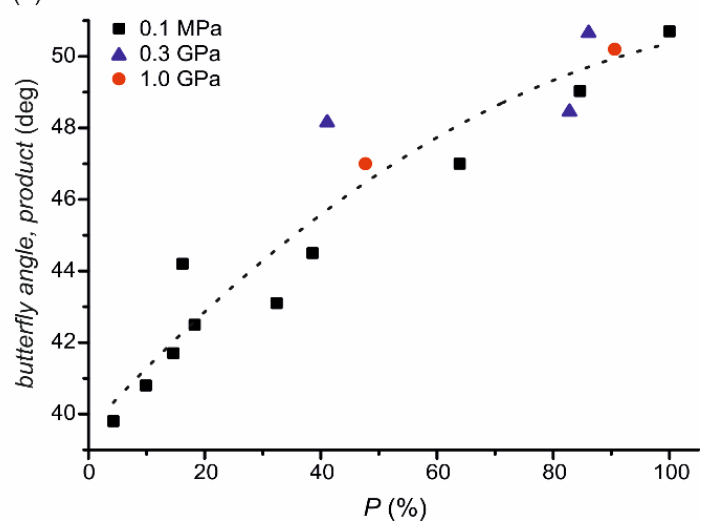

Figure 4. Changes in the "butterfly" angle for (a) the reactant and (b) the product molecule along with the reaction progress. The values for $0.1 \mathrm{MPa}$ were calculated on the ground of the data taken from [5]. Standard uncertainties are in ranges $0.07-0.9^{\circ}, 0.5-3^{\circ}$ and $0.5-4^{\circ}$ for $0.1 \mathrm{MPa}, 0.3 \mathrm{GPa}$ and 1.0 GPa, respectively.

In ambient conditions the orientation of molecules in the unit cell changed during the crystal phototransformation [5]. The situation is different in the case of the high-pressure conditions, where the molecular orientation is constant until ca. $90 \%$ of the phototransformation and only alters in the final stage (Figure 5). The reason for the constancy observed is that under high pressure the molecules have less space for movement (see Figure 2). The reactant molecules have the possibility to change their orientation only when a big number of the product molecules is present in the crystal, since the volume of the product molecule is smaller $\left(448 \AA^{3}\right)$ than the volume of the reactant molecule $\left(461 \AA^{3}\right)$. However, the changes are very small $\left(\mathrm{ca} .5^{\circ}\right)$, since the product molecules fit well between the reactant molecules.

(a)

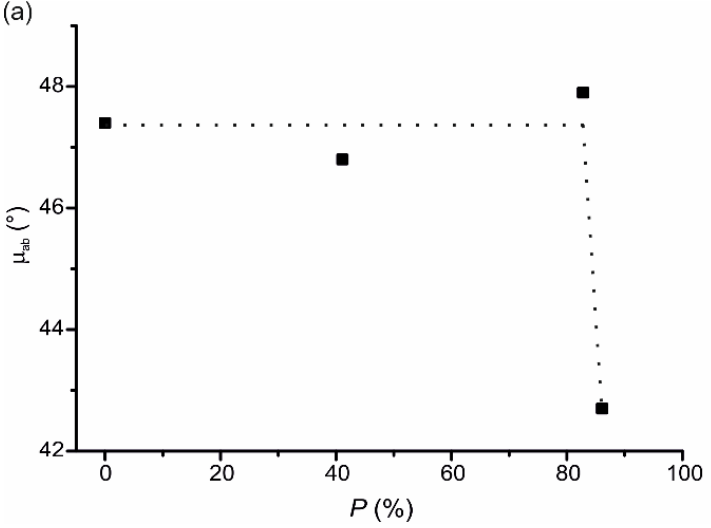

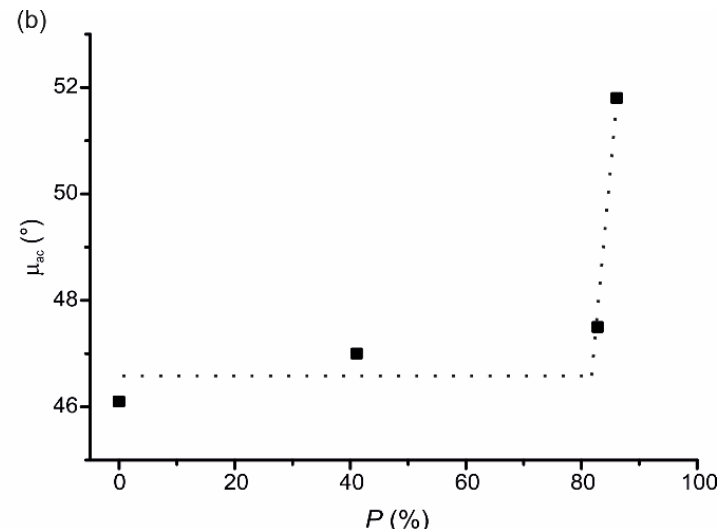

Figure 5. Changes in the angle between the best plane of the anthracene moiety and (a) the $a b$ plane and (b) the $a c$ plane at $0.3 \mathrm{GPa}$. For the $b c$ plane the molecular orientation is statistically constant and ca. $90^{\circ}$ (not shown in the figure). Similar relationships are also observed for 1.0 GPa.

Some geometrical changes along with the crystal phototransformation are also observed for the $\mathrm{C}-\mathrm{H} \cdots \pi$ interactions between the $\mathrm{C} 15$ atom and the middle ring of the anthracene moiety of the nearest neighbouring molecule. These interactions in the pure reactant crystal at $0.1 \mathrm{MPa}, 0.3 \mathrm{GPa}$ and $1.0 \mathrm{GPa}$ were presented on the Hirshfeld surfaces as red areas (see Figure 3). As can be noticed, the higher the pressure, the shorter the intermolecular contacts are. The donor-to-acceptor distance decreases nonlinearly with the increase in pressure (Figure 6), which is understandable since the intermolecular distances are harder to be deformed at higher pressure. For 1.0 GPa the value of this distance is the shortest and equals $3.44,3.53$ and $3.68 \AA$ for $0,47.7$ and $90.6 \%$ of the phototransformation progress. The value of the respective contact for the product for the $90.6 \%$ progress is $3.70 \AA$. Hence, the conclusion is that 
the distance between the donor and the acceptor increases with the reaction progress towards the value observed for the product molecule. This tendency is the same in high-pressure and ambient conditions.

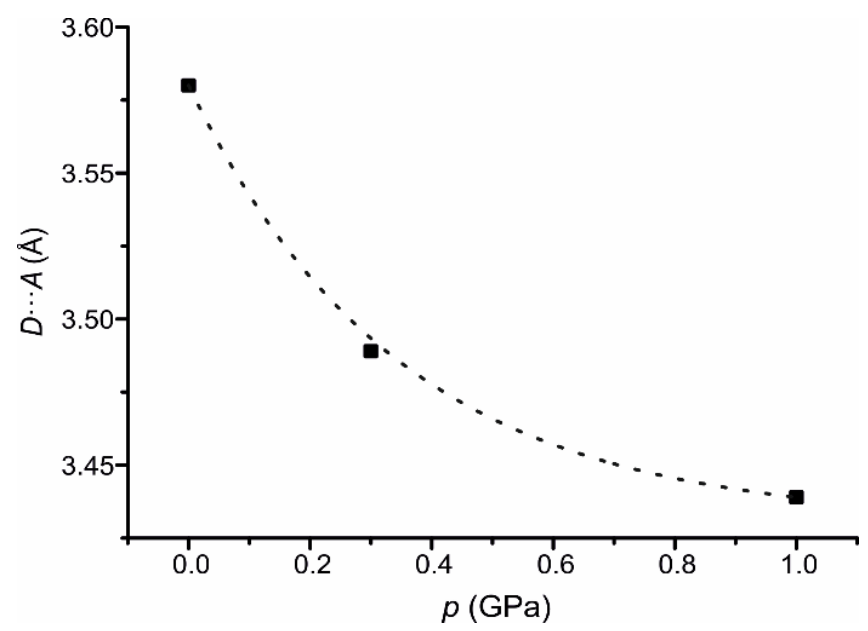

Figure 6. Changes in the donor $\cdots$ acceptor distance for the $\mathrm{C}-\mathrm{H} \cdots \pi$ interactions for the pure reactant crystal along with the increase in pressure. The data for 0.1 MPa were taken from [5].

It results from our previous studies concerning photochemical reactions in crystals that the atoms which take part in the reaction change the distance between them $(D)$ along with the progress of the crystal transformation. However, the character of the changes depended on the type of reaction. For instance, in the case of the intermolecular [2 +2$]$ cycloaddition that distance decreased in a linear manner from the beginning of the transformation [29-32]. Additionally, for the intramolecular Norrish-Yang reaction (where a cyclobutane ring is also formed) that distance was constant for a long time and only at the end of the transformation decreased [21,33-35]. A very unusual relationship was noticed in the case of (1) studied in ambient conditions [5]. Namely, the relationship had a step-like shape: the $D$ distance was constant for a certain time, after which it decreased and from ca. $40 \%$ of the transformation progress it was again constant. The observed height of the above-mentioned step was ca. $0.1 \AA$, which can be regarded as a significant value when we take into account that the $D$ distance is an intramolecular parameter. Quite similar behaviour is observed by us for the data at high pressure: for $0.3 \mathrm{GPa}$ and $1.0 \mathrm{GPa}$ the $D$ distance is almost constant until ca. $40 \%$ of the transformation progress and in the final stages it is much smaller than at the beginning and with a similar value as for the ambient conditions. The relationship for $0.3 \mathrm{GPa}, 1.0 \mathrm{GPa}$ and additionally for $0.1 \mathrm{MPa}$ is shown in Figure 7.

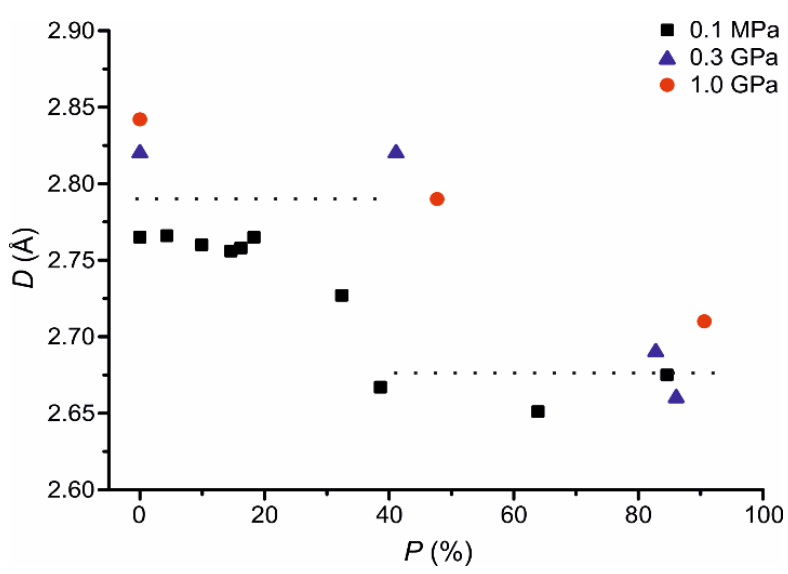

Figure 7. Changes in the $D$ distance between directly reacting carbon atoms along with the reaction progress. The data for $0.1 \mathrm{MPa}$ were taken from [5]. Standard uncertainties are in ranges $0.002-0.03 \AA$, $0.02-0.05 \AA$ and $0.017-0.05 \AA$ for $0.1 \mathrm{MPa}, 0.3 \mathrm{GPa}$ and $1.0 \mathrm{GPa}$, respectively. For the pure reactant crystals, the difference between $D$ at $0.1 \mathrm{MPa}$ and $1.0 \mathrm{GPa}$ is statistically significant at the $3 \sigma$ level. 


\section{Conclusions}

Crystals of bi(anthracene-9,10-dimethylene) undergo the $[4+4]$ photocycloaddition both in ambient and high-pressure conditions. The studies carried out by us showed that the formation of the photoproduct is not halted nor significantly hindered in single crystals under applied high pressure and that the reverse reaction does not dominate. It was possible to keep the photoproduct during the time sufficient for the high-pressure X-ray data collection (over $24 \mathrm{~h}$ ), and owing to this it was possible to determine the high-pressure crystal structures at an atomic level for various stages of the crystal phototransformation. This is in contrast to a polymer matrix, where the higher the pressure, the more difficult it is to keep the photoproduct, and above 2.0 GPa, its formation is almost entirely inhibited [2]. The analysis of the structural data revealed that high pressure itself does not influence significantly the intramolecular distances, angles, molecular shape and molecular orientation, but decreases the intermolecular distances, free space volume and unit cell volume. However, with the progress of the phototransformation, the above-listed parameters alter their values towards those observed for the pure product crystal. The photo-induced structural changes are also reflected in the cell parameters; nevertheless, the initial increase in the unit cell volume is diminished by high pressure.

Author Contributions: The manuscript was written through contributions from J.B. and I.T.-T. All authors have read and agreed to the published version of the manuscript.

Funding: This research received no external funding.

Acknowledgments: This work was financed by the statutory activity subsidy from the Polish Ministry of Science and Higher Education for the Faculty of Chemistry of the Wroclaw University of Science and Technology.

Conflicts of Interest: The authors declare no conflict of interest.

\section{References}

1. Kaupp, G. Mechanochemistry: The varied applications of mechanical bond-breaking. CrystEngComm 2009, 11, 388-403. [CrossRef]

2. Jezowski, S.R.; Zhu, L.; Wang, Y.; Rice, A.P.; Scott, G.W.; Bardeen, C.J; Chronister, E.L. Pressure catalyzed bond dissociation in an anthracene cyclophane photodimer. J. Am. Chem. Soc. 2012, 134, 7459-7466. [CrossRef]

3. Tong, F.; Cruz, C.D.; Jezowski, S.R.; Zhou, X.; Zhu, L.; Al-Kaysi, R.O.; Chronister, E.L.; Bardeen, C.J. Pressure dependence of the forward and backward rates of 9-tert-butylanthracene dewar isomerization. J. Phys. Chem. A 2014, 118, 5349-5354. [CrossRef] [PubMed]

4. James, S.L.; Friscic, T. Mechanochemistry. Chem. Soc. Rev. 2013, 42, 7494-7496. [CrossRef]

5. Trzop, E.; Turowska-Tyrk, I. Monitoring structural transformations in crystals. 12. Course of an intramolecular $[4+4]$ photocycloaddition in a crystal. Acta Crystallogr. Sect. B Struct. Sci. 2008, 64, 375-382. [CrossRef]

6. Golden, J.H. Bi(anthracene-9,10-dimethylene) (Tetrabenzo-[2,2]paracyclophane]. J. Chem. Soc. 1961, 3741-3748. [CrossRef]

7. Ferguson, J.; Mau, A.W.H. A spectroscopic study of the photodimerization of anthracene sandwich dimers in dianthracene. Mol. Phys. 1974, 27, 377-387. [CrossRef]

8. Ferguson, J.; Mau, A.W.H.; Morris, J.M. Spectra of dimers of anthracene and its derivatives. I. Sandwich dimers. Aust. J. Chem. 1973, 26, 91-102. [CrossRef]

9. Wada, A.; Tanaka, J. The molecular structure of bi(anthracene-9,10-dimethylene), $\mathrm{C}_{32} \mathrm{H}_{24}$. Acta Crystallogr. Sect. B 1977, 33, 355-360. [CrossRef]

10. Dougherty, D.A.; Choi, C.S.; Kaupp, G.; Buda, A.B.; Rudziński, J.M.; Osawa, E. Effects of substituents on the length of central $\mathrm{C}\left(s p^{3}\right)-\mathrm{C}\left(s p^{3}\right)$ bond in anthracene photodimers and related molecules. J. Chem. Soc. Perkin Trans. 2 1986, 1063-1070. [CrossRef]

11. Kaupp, G. Cyclovinylogous [2 $\rightarrow 2 \sigma]$ Photoadditions. Angew. Chem. Int. Ed. 1972, 11, 313-314. [CrossRef]

12. Kaupp, G. AFM and STM in photochemistry including photon tunneling. Adv. Photochem. 1995, 19, 119-177. [CrossRef]

13. Milledge, H.J. The automatic selection of molecular crystal structures by combining stereochemical criteria and high-speed computing. Proc. Roy. Soc. A 1962, 267, 566-589. [CrossRef]

14. Ehrenberg, M. The crystal structure of di-para-anthracene. Acta Crystallogr. 1966, 20, 182-186. [CrossRef] 
15. Harada, J.; Ogawa, K.; Tomoda, S. The central C-C bond length in the bi(anthracene-9,10-dimethylene) photoisomer: Unusual elongation and crystalline state reaction. Chem. Lett. 1995, 24, 751-752. [CrossRef]

16. Merrill, L.; Bassett, W.A. Miniature diamond anvil pressure cell for single crystal X-ray diffraction studies. Rev. Sci. Instrum. 1974, 45, 290-294. [CrossRef]

17. Angel, R.J.; Allan, D.R.; Miletich, R.; Finger, L.W. The use of quartz as an internal pressure standard in high-pressure crystallography. J. Appl. Crystallogr. 1997, 30, 461-466. [CrossRef]

18. Rigaku Oxford Difraction, CrysAlisPro Rigaku Oxford Diffraction, Wrocław, Poland.

19. Sheldrick, G.M. A short history of SHELX. Acta Crystallogr. Sect. A Found. Crystallogr. 2008, 64, 112-122. [CrossRef]

20. Sheldrick, G.M. Crystal structure refinement with SHELXL. Acta Crystallogr. Sect. C Struct. Chem. 2015, 71, 3-8. [CrossRef]

21. Konieczny, K.; Bakkowicz, J.; Turowska-Tyrk, I. Structural transformations in crystals induced by radiation and pressure. Part 2. The path of the photochemical intramolecular reaction in crystals at different pressures. CrystEngComm 2015, 17, 7693-7701. [CrossRef]

22. Groom, C.R.; Bruno, I.J.; Lightfoot, M.P.; Ward, S.C. The Cambridge Structural Database. Acta Crystallogr. Sect. B Struct. Sci. 2016, 72, 171-179. [CrossRef] [PubMed]

23. Abrahams, S.C.; Robertson, J.M.; White, J.G. The crystal and molecular structure of naphthalene. I. X-ray measurements. Acta Crystallogr. 1949, 2, 233-238. [CrossRef]

24. Fabbiani, F.P.A.; Allan, D.R.; Parsons, S.; Pulham, C.R. Exploration of the high-pressure behaviour of polycyclic aromatic hydrocarbons: Naphthalene, phenanthrene and pyrene. Acta Crystallogr. Sect. B Struct. Sci. 2006, 62, 826-842. [CrossRef] [PubMed]

25. Budzianowski, A.; Katrusiak, A. Pressure-frozen benzene I revisited. Acta Crystallogr. Sect. B Struct. Sci. 2006, 62, 94-101. [CrossRef]

26. Macrae, C.F.; Edgington, P.R.; McCabe, P.; Pidcock, E.; Shields, G.P.; Taylor, R.; Towler, M.; van de Streek, J. Mercury: Visualization and analysis of crystal structures. J. Appl. Crystallogr. 2006, 39, 453-457. [CrossRef]

27. Turner, M.J.; McKinnon, J.J.; Wolff, S.K.; Grimwood, D.J.; Spackman, P.R.; Jayatilaka, D.; Spackman, M.A. CrystalExplorer17. University of Western Australia. 2017. Available online: https://crystalexplorer.scb.uwa. edu.au/ (accessed on 8 June 2017).

28. Spackman, M.A.; Jayatilaka, D. Hirshfeld surface analysis. CrystEngComm 2009, 11, 19-32. [CrossRef]

29. Fernandes, M.A.; Levendis, D.C. Photodimerisation of the $\alpha^{\prime}$-polymorph of ortho-ethoxy-trans-cinnamic acid occurs via a two-stage mechanism at $343 \mathrm{~K}$ yielding $100 \% \alpha$-truxillic acid. Acta Crystallogr. Sect. B Struct. Sci. 2004, 60, 315-324. [CrossRef]

30. Turowska-Tyrk, I. Structural transformations in a crystal during the photochemical reaction of 2-benzyl-5benzylidenecyclopentanone. Chem. Eur. J. 2001, 7, 3401-3405. [CrossRef]

31. Turowska-Tyrk, I. Monitoring structural transformations in crystals. 5. A topotactic [2+2]-photodimerization reaction. Acta Crystallogr. Sect. B Struct. Sci. 2003, 59, 670-675. [CrossRef]

32. Turowska-Tyrk, I.; Trzop, E. Monitoring structural transformations in crystals. 6. The [4+4] photodimerization of 9-methylanthracene. Acta Crystallogr. Sect. B Struct. Sci. 2003, 59, 779-786. [CrossRef]

33. Turowska-Tyrk, I.; Trzop, E.; Scheffer, J.R.; Chen, S. Monitoring structural transformations in crystals. 8. Monitoring molecules and a reaction center during a solid-state Yang photocyclization. Acta Crystallogr. Sect. B Struct. Sci. 2006, 62, 128-134. [CrossRef] [PubMed]

34. Turowska-Tyrk, I.; Bakkowicz, J.; Scheffer, J.R. Monitoring structural transformations in crystals. 11. Yang photocyclizations-one type of reaction, but diversity of structural changes. Acta Crystallogr. Sect. B Struct. Sci. 2007, 63, 933-940. [CrossRef] [PubMed]

35. Konieczny, K.; Bakkowicz, J.; Siedlecka, R.; Galica, T.; Turowska-Tyrk, I. Photoinduced structural changes as the factor influencing the direction of the photochemical reaction in the crystal. Cryst. Growth Des. 2017, 17, 1347-1352. [CrossRef]

Publisher's Note: MDPI stays neutral with regard to jurisdictional claims in published maps and institutional affiliations. 